\title{
Agency Problem and Hedging in Agri-Food Chains: Model and Application
}

\author{
JOHN K. M. KUWORNU \\ Department of Agricultural Economics and Agribusiness, \\ University of Ghana, Legon, Accra, Ghana \\ W. ERNO KUIPER \\ Department of Social Sciences, Wageningen University, Wageningen, The Netherlands
}

JOOST M. E. PENNINGS

Department of Finance and Department of Marketing, Maastricht University,

Maastricht, The Netherlands

The last 4 decades have seen the transformation of food supply chains from being supply driven to becoming much more closely integrated with consumer demand. With this development, the transaction mechanism in food marketing channels has changed from an open-market mechanism to coordination through the use of contract-supply arrangements between farmers and food processors and retailers. In this article, we assess the interaction of marketing channel members through the use of contracts and its impact on incentives, coordination costs, risk aversion, risk allocation, and risk management strategies. For this purpose we specify a 3-stage principal-agent supply chain model involving producers, wholesalers, retailers, and a futures market. We compare the situation with and without a futures market. The empirical results regarding the Dutch ware potato marketing channel during 1971 to 2003 reveal that as a result of increases in incentives to producers and wholesalers, the coordination costs of the marketing channel decreased significantly, both with and without futures trade. The coordination costs of the marketing channel in the case with a futures market appear to be lower than without futures, demonstrating the informational (i.e., price discovery) role of futures markets.

Address correspondence to John K. M. Kuwornu, Lecturer, Department of Agricultural Economics and Agribusiness, University of Ghana, P.O. Box LG 68, Legon, Accra, Ghana. E-mail: jkuwornu@ug.edu.gh 
KEYWORDS agency theory, coordination costs, food marketing channels, hedge ratio, risk

\section{INTRODUCTION}

In the last 4 decades, food marketing channels (FMCs) have been transformed from supply-oriented chains into demand-oriented chains, which has been termed chain reversal or structural changes in food marketing channels (e.g., Boehlje, 1996; Folkerts \& Koehorst, 1998). This transformation has been characterized by product differentiation, competition, globalization, and consumers' desire for quality and safe foods. Another issue worth mentioning is the consolidation and concentration of food retailers and the resulting bargaining power imbalance vis-à-vis their suppliers (e.g., Competition Commission, 2000; Hingley, 2005; Reimer, 2006). These developments in FMCs have implications for strategies of upstream channel members (i.e., producers and wholesalers). For example, the contractual relationships (spot, forward, and futures contracts) among marketing channel members (MCMs) are influenced by the bargaining power of one MCM vis-à-vis the other MCMs (Pennings \& Leuthold, 2000).

More specifically, the outcomes of contract negotiations among MCMs have an impact on the financial risk allocation in the channel. Numerous authors have investigated financial risk allocation in FMCs (e.g., Knoeber \& Thurman, 1995; Kuwornu, Kuiper, \& Pennings, 2004; Kuwornu, Kuiper, Pennings, \& Meulenberg, 2004; Martin, 1997). However, a limitation of these studies is that they focus on only two stages of the marketing channel. For instance, Knoeber and Thurman (1995) have investigated financial risk allocation between farmers and integrator companies in the U.S. broiler industry, in which they found that financial risk has shifted from farmers to integrator companies. Moreover, as a consequence of financial risks, MCMs may wish to hedge against output and input price risk in futures markets. This has led various authors to estimate optimal hedge ratios for producers (e.g., Ederington, 1979; Dawson, Tiffin, \& White, 2000; Kuwornu, Kuiper, Pennings, \& Meulenberg, 2005b; Pennings \& Meulenberg, 1997).

The unanswered questions regarding the preceding discussion are the following: what is the role of futures markets regarding risk allocations in multistage marketing channels (commonly) involving producers, wholesalers, and retailers? Given that financial risk allocation has an impact on MCMs performance objectives in case of risk-averse MCMs and that futures markets can reallocate risk in the marketing channel, then what should be the optimal hedging strategy for the risk-averse MCMs? What are the coordination costs in the marketing channel when MCMs trade in futures markets as compared to the case that these MCMs do not trade in futures markets? Moreover, to the best of our knowledge, research effort that integrates risk allocation 
(or risk aversion) in FMCs and the estimation of the optimal hedge ratio is scanty (e.g., Mattos, Garcia, \& Pennings, 2008; Pennings, 2004). For example, Pennings (2004) specified a model to estimate static forward contract ratios to investigate the role of forward contracts in reducing cash-flow volatility of various meat (beef, chicken, and pork) departments of European retailers. However, his research addressed only the retail stage of the marketing channel.

Moreover, as risk aversion of MCMs may change over time, it is, therefore, important that dynamic hedge ratios be considered. This study fills a gap in the existing literature by specifying a model that integrates optimal dynamic hedge ratios and risk allocations in FMCs involving producers, wholesalers, and retailers. Such an integrated framework improves our understanding of how MCMs react to risk in spot markets. Thus, the relationship between the degree of risk aversion and the extent of hedging is a key issue in this study. The article's contribution in this respect is the estimation of optimal hedge ratios for MCMs, while taking the contractual relationships among these MCMs into account. Subsequently, the objectives of this study are threefold. First, it seeks to extend the above-mentioned empirical investigations to marketing channels involving three stages while allowing risk-averse channel members to trade in a futures market. Second, it derives and estimates dynamic optimal hedge ratios for the risk-averse MCMs. Third, it addresses issues of incentives and coordination costs in the context of a FMC when MCMs trade in the futures market, compared with the case that MCMs do not use futures.

To answer the above-mentioned research questions, we specify a three-stage principal-agent marketing channel model for producers, wholesalers, and retailers extended with a futures market. The principal-agent model (e.g., Birchler \& Bütler, 2007; Furubotn \& Richter, 1997; Gibbons, 2005; Milgrom \& Roberts, 1992) is part of the agency theory framework. Originated in the information economics literature, agency theory studies problems that arise when one party (the principal) delegates work to another party (the agent). The core idea of agency theory is that principal-agent relationships should reflect efficient information and risk-bearing costs, incentive alignments, and the contract as the unit of analysis. The classic model of agency theory involves an agent who performs a task for the principal. The principal values the agent's realized performance and pays the agent compensation, as specified by a contract. However, there are some problems the principal has to deal with. The first one is the information asymmetry between principal and agent; the principal cannot fully observe the effort of the agent. The second problem is goal conflict between principal and agent. That is, the information asymmetry between the principal and the agent is not a problem per se; it becomes a problem when the principal and the agent have different goals. The third is the problem of risk sharing. This arises when the agent is risk-averse, and alternative incentive arrangements 
in contracts change the agent's risk position. Numerous researchers have used agency theory to model contractual relationships (e.g., Eisenhardt, 1989; Zhao, 2005). In this study, we seek to link the above-mentioned agency problems to contractual relationships and hedging positions of MCMs.

Regarding the MCMs (producers, wholesalers, and retailers) in our empirical application (and in many other FMCs), observation has shown that, in terms of scale of operation, retailers are larger than wholesalers and, in turn, wholesalers are larger than producers. Our model allows risk-averse MCMs to trade in the futures market to enable them to hedge against their income risk inherent in the spot market. We assume that the retailers, carrying a broad assortment of products and hence, being able to diversify, are risk-neutral, whereas producers and wholesalers, who operate on relatively small scales and can therefore hardly diversify against risks, are considered risk-averse. Consequently, our model assumes the risk-neutral retailers to trade in only the spot markets, whereas the risk-averse producers and wholesalers trade in both the spot and the futures markets to enable them to hedge against the risks in the spot market.

\section{THEORETICAL MODEL}

Throughout the model, we consider a product that is produced by farmers, processed and distributed to retailers by wholesalers, and finally sold to consumers by retailers. The retail value of the product is specified as

$$
x=e+\varepsilon
$$

where $x$ is the actual retail value, $e$ is the expectation of the retail value at the time of the contract negotiations in the marketing channel, and $\varepsilon$ is the random component of the retail value, which is assumed to be normally distributed with mean zero and variance $\sigma^{2}$.

We assume a hypothetical linear contract between the retailer and the wholesaler as follows:

$$
W_{w}=\alpha_{w} x+\beta_{w}
$$

where $W_{w}$ is the total compensation payment from the retailer to the wholesaler, $\alpha_{w}$ is the incentive parameter, $\alpha_{w} x$ is the variable compensation payment, and $\beta_{w}$ is the fixed compensation. Similarly, the contractual relationship between the wholesaler and the producer is specified as

$$
W_{p}=\alpha_{p} \alpha_{w} x+\beta_{p}
$$

where $W_{p}$ is the total compensation payment from the wholesaler to the producer, $\alpha_{p}$ is the variable-revenue sharing parameter between the wholesaler 
and the producer (i.e., the proportion of the wholesaler's variable revenue that is received by the producer), $\alpha_{p} \alpha_{w}$ is the actual incentive parameter from the wholesaler to the producer, and $\alpha_{p} \alpha_{w} x$ and $\beta_{p}$ are the variable and fixed compensation payments to the producer, respectively. ${ }^{1}$

Imposing increasing marginal costs, the cost function of the wholesaler is specified as

$$
C_{w}=0.5 c_{w} e^{2}+d_{w}
$$

Similarly, the producer's cost of effort is specified as

$$
C_{p}=0.5 c_{p} e^{2}+d_{p}
$$

where $d_{w}$ and $d_{p}$ denote deterministic trend terms that may reflect technological changes in production. Note that the cost functions concern expected costs, not actual costs, because their argument is given by $e$. This argument also implies that production cost may increase, either by extending the production quantity or by improving the quality of the product as reflected by a higher expected output price.

Net of fixed retail costs, the retailers' profit is

$$
\pi_{r}=x-W_{w}
$$

which has the following variance

$$
\operatorname{Var}\left(\pi_{r}\right)=\left(1-\alpha_{w}\right)^{2} \sigma^{2}
$$

as can be seen by substituting Eqs. (1) and (2) in Eq. (6). As the product is one of the many stock-keeping units in the assortment of the retailer, we assume that the retailer does not care about this variance. In contrast, in the model we allow the risk-averse producers and wholesalers to trade futures contracts besides their contractual relationships in the marketing channel in order to hedge against risks in the spot market. Accordingly, the producer's profit, $\pi_{p}$, resulting from selling futures contracts of his or her products and from the contractual relationship with the wholesaler, is given by

$$
\pi_{p}=W_{p}-C_{p}+Z_{p}\left(F_{t, t-1}-F_{t, t}\right)
$$

where $Z_{p}\left(F_{t, t-1}-F_{t, t}\right)$ represents the producer's gain or loss from selling futures contracts, in which $Z_{p}$ is the volume of futures contracts sold at time $t-1$; that is, the time of the contract negotiations in the marketing channel; $F_{t, t-1}$ is the futures price at time $t-1$; and $F_{t, t}$ is the futures price at time $t$. Thus, the producer's result of having a hedging position can be either positive or negative, depending on whether the futures price at which he or she 
closed the futures position is below or above the futures price at which $\mathrm{s} / \mathrm{he}$ initiated the position. ${ }^{2}$ The difference in the futures price between time $t-1$ and $t$ is assumed to follow a random walk with drift as follows:

$$
F_{t, t-1}-F_{t, t}=\mu_{F}+\varepsilon_{F t}
$$

where $\mu_{F}$, denoting the drift term, reflects storage costs and interest costs in futures trade, and $\varepsilon_{F t}$ is the error term with zero mean and variance $\sigma_{F}^{2}$. In the same vein, the wholesaler's profit from buying futures contracts of the products for wholesaling and from the contractual relationship with the retailer is given as

$$
\pi_{w}=W_{w}-C_{w}-W_{p}-Z_{w}\left(F_{t, t}-F_{t, t-1}\right)
$$

where $Z_{w}\left(F_{t, t}-F_{t, t-1}\right)$ represents the wholesaler's gain or loss from buying futures contracts, in which $Z_{w}$ is the volume of futures contracts sold at time $t-1$. Thus, also the wholesaler's result of having a hedging position can be either positive or negative depending on whether the futures price at which he or she closed the futures position is below or above the futures price at which he or she initiated the position. ${ }^{3}$

Not only do producers and wholesalers form expectations regarding their respective profits, they are not indifferent to the uncertainty of their expectations either. In this article, we measure the uncertainty in producers' and wholesalers' profits by their respective variances as a proxy for their risk. The variance of producers' profit is

$$
\operatorname{Var}\left(\pi_{p}\right)=\alpha_{p}^{2} \alpha_{w}^{2} \sigma^{2}+z_{p}^{2} \sigma_{F}^{2}+2 \alpha_{p} \alpha_{w} z_{p} \sigma_{\varepsilon F}
$$

as can be derived from substituting (1), (3), and (9) into (8). Similarly, the variance of wholesalers' profit is found as

$$
\operatorname{Var}\left(\pi_{w}\right)=\left(1-\alpha_{p}\right)^{2} \alpha_{w}^{2} \sigma^{2}+z_{w}^{2} \sigma_{F}^{2}-2\left(1-\alpha_{p}\right) \alpha_{w} z_{w} \sigma_{\varepsilon F}
$$

after substituting (1) through (3) and (9) in (10). Given that the risk aversion of producers and wholesalers comply with the constant absolute risk aversion (CARA) model and that their profits are normally distributed, then their objective functions are equivalent to the maximization of their respective certainty equivalents of profits given as

$$
C E(\pi)=E(\pi)-0.5 \rho \operatorname{Var}(\pi)
$$

where $C E(\pi)$ is the certainty equivalent of profit, $E(\pi)$ is the expectation of profit, and $0.5 \rho \operatorname{Var}(\pi)$ is the risk premium in which $\rho$ is the CARA coefficient and $\operatorname{Var}(\pi)$ is the variance of profits. Note that the expectations in $C E(\pi)$ are common to all MCMs and conditional on the information set at time $t-1$. 
Accordingly, the producer's objective function reads as

$$
\begin{aligned}
\max _{e, Z_{p}}\{ & \alpha_{p} \alpha_{w} e+\beta_{p}-d_{p}-0.5 c_{p} e^{2}+\mu_{F} z_{p}-0.5 \rho_{p} \alpha_{p}^{2} \alpha_{w}^{2} \sigma^{2}-0.5 \rho_{p} z_{p}^{2} \sigma_{F}^{2} \\
& \left.-\rho_{p} \alpha_{p} \alpha_{w} z_{p} \sigma_{\varepsilon F}\right\}
\end{aligned}
$$

of which the first order conditions are

$$
e=\alpha_{p} \alpha_{w} / c_{p}
$$

and

$$
Z_{p}=\left(\mu_{F}-\rho_{p} \alpha_{p} \alpha_{w} \sigma_{\varepsilon F}\right) / \rho_{p} \sigma_{F}^{2}
$$

In the contract offered to the producer, the wholesaler is subjected to the participation constraint (reservation utility constraint) and the incentive compatibility constraint. ${ }^{4}$ The participation constraint suggests that the producer equates his/her reservation wage $\bar{W}_{p}$ to his/her certainty equivalent of profit $C E\left(\pi_{p}\right)$ from which the producer's fixed compensation $\beta_{p}$ is then derived by inserting $e$ from (15) and $Z_{p}$ from (16) into the certainty equivalent of profit in (14), obtaining

$$
\begin{aligned}
\beta_{p}= & \bar{W}_{p}+d_{p}-0.5 \alpha_{p}^{2} \alpha_{w}^{2} / c_{p}-0.5 \mu_{F}^{2} / \rho_{p} \sigma_{F}^{2}+0.5 \rho_{p} \alpha_{p}^{2} \alpha_{w}^{2} \sigma^{2}+\alpha_{p} \alpha_{w} \mu_{F} \sigma_{\varepsilon F} / \sigma_{F}^{2} \\
& -0.5 \rho_{p} \alpha_{p}^{2} \alpha_{w}^{2} \sigma_{\varepsilon F}^{2} / \sigma_{F}^{2}
\end{aligned}
$$

Having derived the conditions for the parameters in the contract offered by the wholesaler to the producer that allow the parameters be optimal to the wholesaler given the restriction imposed by the participation constraint, we now turn to the derivation of the optimality conditions for the parameters in the contract offered by the retailer to the wholesaler. From (1) through (4), (10), (12), and (13), the wholesaler's certainty equivalent of profit is obtained as

$$
\begin{aligned}
C E\left(\pi_{w}\right)= & \left(1-\alpha_{p}\right) \alpha_{w} e+\beta_{w}-0.5 c_{w} e^{2}-d_{w}-\beta_{p}-\mu_{F} Z_{w} \\
& -0.5 \rho_{w}\left(1-\alpha_{p}\right)^{2} \alpha_{w}^{2} \sigma^{2}-0.5 \rho_{w} Z_{w}^{2} \sigma_{F}^{2}+\rho_{w}\left(1-\alpha_{p}\right) \alpha_{w} Z_{w} \sigma_{\varepsilon F}
\end{aligned}
$$

Inserting $e$ from (15) and $\beta_{p}$ from (17) into (18), the risk-averse wholesaler maximizes the certainty equivalent of profit, $C E\left(\pi_{w}\right)$, as follows:

$$
\begin{aligned}
\operatorname{Max}_{\alpha_{p}, z_{w}}\{( & \left.-\alpha_{p}\right) \alpha_{w}^{2} \alpha_{p} / c_{p}+\beta_{w}-d_{w}-0.5 c_{w} \alpha_{p}^{2} \alpha_{w}^{2} / c_{p}^{2}-\bar{W}_{p}-d_{p}+0.5 \alpha_{p}^{2} \alpha_{w}^{2} / c_{p} \\
& +0.5 \mu_{F}^{2} / \rho_{p} \sigma_{F}^{2}-0.5 \rho_{p} \alpha_{p}^{2} \alpha_{w}^{2} \sigma^{2}-\alpha_{p} \alpha_{w} \mu_{F} \sigma_{\varepsilon F} / \sigma_{F}^{2}+0.5 \rho_{p} \alpha_{p}^{2} \alpha_{w}^{2} \sigma_{\varepsilon F}^{2} / \sigma_{F}^{2} \\
& \left.-\mu_{F} Z_{w}-0.5 \rho_{w}\left(1-\alpha_{p}\right)^{2} \alpha_{w}^{2} \sigma^{2}-0.5 \rho_{w} Z_{w}^{2} \sigma_{F}^{2}+\rho_{w}\left(1-\alpha_{p}\right) \alpha_{w} Z_{w} \sigma_{\varepsilon F}\right\}
\end{aligned}
$$


The first-order conditions yield

$$
\begin{aligned}
\alpha_{p}= & \left(1-c_{p} \mu_{F} \sigma_{\varepsilon F} / \alpha_{w} \sigma_{F}^{2}+c_{p} \rho_{w} \sigma^{2}-c_{p} \rho_{w} Z_{w} \sigma_{\varepsilon F} / \alpha_{w}\right) \\
& /\left(1+c_{w} / c_{p}+c_{p} \rho_{p} S+c_{p} \rho_{w} \sigma^{2}\right)
\end{aligned}
$$

and

$$
Z_{w}=\left[\rho_{w}\left(1-\alpha_{p}\right) \alpha_{w} \sigma_{\varepsilon F}-\mu_{F}\right] / \rho_{w} \sigma_{F}^{2}
$$

where

$$
S \equiv\left(\sigma^{2} \sigma_{F}^{2}-\sigma_{\varepsilon F}^{2}\right) / \sigma_{F}^{2}
$$

Next, like the producer, the wholesaler considers a participation constraint according to which the retailer has to equate the certainty equivalent of the wholesaler's profit, $C E\left(\pi_{w}\right)$, to the wholesaler's reservation wage, $\bar{W}_{w}$. From this condition, and after inserting $Z_{w}$ from (21) into (19), the wholesaler's fixed compensation is derived as

$$
\begin{aligned}
\beta_{w}= & \bar{W}_{w}+d_{w}+\bar{W}_{p}+d_{p}-\alpha_{w}^{2} \alpha_{p} / c_{p}+0.5 c_{w} \alpha_{p}^{2} \alpha_{w}^{2} / c_{p}^{2}+0.5 \alpha_{p}^{2} \alpha_{w}^{2} / c_{p} \\
& -0.5 \mu_{F}^{2} / \rho_{p} \sigma_{F}^{2}+0.5 \rho_{p} \alpha_{p}^{2} \alpha_{w}^{2} S+\mu_{F} \alpha_{w} \sigma_{\varepsilon F} / \sigma_{F}^{2}-0.5 \mu_{F}^{2} / \rho_{w} \sigma_{F}^{2} \\
& +0.5 \rho_{w}\left(1-\alpha_{p}\right)^{2} \alpha_{w}^{2} S
\end{aligned}
$$

Regarding the variable compensation for the wholesaler we can substitute (21) in (20) to obtain the following expression for the revenue sharing parameter $\alpha_{p}$ in the wholesaler's contract with the producer

$$
\alpha_{p}=\left[1+c_{p} \rho_{w} S\right] /\left[1+c_{w} / c_{p}+c_{p}\left(\rho_{p}+\rho_{w}\right) S\right]
$$

We now turn to the objective function of the risk-neutral retailer. From Eqs. (1), (2), (6), (15), and (23), the risk-neutral retailer maximizes the expectation of profits as follows:

$$
\begin{aligned}
\operatorname{Max}_{\alpha_{w}}\left\{\alpha_{p} \alpha_{w} / c_{p}\right. & -\bar{W}_{w}-d_{w}-\bar{W}_{p}-d_{p}-0.5 c_{w} \alpha_{p}^{2} \alpha_{w}^{2} / c_{p}^{2}-0.5 \alpha_{p}^{2} \alpha_{w}^{2} / c_{p} \\
& +0.5 \mu_{F}^{2} / \rho_{p} \sigma_{F}^{2}-0.5 \rho_{p} \alpha_{p}^{2} \alpha_{w}^{2} S-\mu_{F} \alpha_{w} \sigma_{\varepsilon F} / \sigma_{F}^{2}+0.5 \mu_{F}^{2} / \rho_{w} \sigma_{F}^{2} \\
& \left.-0.5 \rho_{w}\left(1-\alpha_{p}\right)^{2} \alpha_{w}^{2} S\right\}
\end{aligned}
$$

for which the first-order condition yields

$$
\begin{aligned}
\alpha_{w}= & {\left[1-c_{p} \mu_{F} \sigma_{\varepsilon F} / \alpha_{p} \sigma_{F}^{2}\right] } \\
& /\left[c_{w} \alpha_{p} / c_{p}+\alpha_{p}+c_{p} \rho_{p} \alpha_{p} S+c_{p} \rho_{w}\left(1-\alpha_{p}\right)^{2} S / \alpha_{p}\right]
\end{aligned}
$$


Recall from the linear contract for the wholesaler as presented in (2) that the revenue sharing parameter is given by $\alpha_{w}$. In the contract for the producer the revenue sharing parameter is $\alpha_{p} \alpha_{w}$. Consequently, if $\alpha_{p}$ was a constant parameter, then both revenue sharing parameters could still be time-varying through $\alpha_{w}$. In line with this notion and for purpose of empirical testing to be discussed in the next two sections, we consider $\alpha_{w}, \beta_{w}, \beta_{p}, \rho_{w}, \rho_{p}, Z_{w}$ and $Z_{p}$ as unknown variables to be solved by Eqs. (15) through (17), (21), (23), (24), and (26). Below, we first discuss the derivation of the solutions for $\rho_{w}$ and $\rho_{p}$.

Equating $\alpha_{w}$ in (15) to $\alpha_{w}$ in (26), we obtain the following expression for the producer's risk parameter:

$$
\rho_{p}=\rho_{w}\left(1-\alpha_{p}\right) / \alpha_{p}+\left(1-\alpha_{p}-\alpha_{p} c_{w} / c_{p}\right) / \alpha_{p} c_{p} S
$$

Next, substituting $\alpha_{w}$ from (15) and $\rho_{p}$ from (27) into (26), we obtain the wholesaler's risk parameter as follows:

$$
\rho_{w}=\left[\left(\sigma_{F}^{2} \alpha_{p}-\sigma_{F}^{2} c_{p} e-c_{p} \mu_{F} \sigma_{\varepsilon F}\right) \alpha_{p}\right] /\left[\left(1-\alpha_{p}\right) c_{p}^{2} e \sigma_{F}^{2} S\right]
$$

Subsequently, substituting $\rho_{w}$ from (28) into (27), we obtain the risk parameter for the producer as

$$
\rho_{p}=\left[\sigma_{F}^{2} \alpha_{p}^{2}-2 \sigma_{F}^{2} \alpha_{p} c_{p} e-\alpha_{p} c_{p} \mu_{F} \sigma_{\varepsilon F}+c_{p} e \sigma_{F}^{2}-\alpha_{p} c_{w} e \sigma_{F}^{2}\right] /\left[\alpha_{p} c_{p}^{2} e \sigma_{F}^{2} S\right]
$$

These risk parameters are one of the determinants of the amount of produce that producers and wholesalers hedge on the futures market. In the model, we assume that the quantity produced, $q$, is the same as the quantity consumed. The optimal hedge ratios for the producers and wholesalers, respectively, are given by ${ }^{5}$

$$
b_{p}^{*}=Z_{p} / E(q)
$$

and

$$
b_{w}^{*}=Z_{w} / E(q)
$$

where $Z_{p}$ and $Z_{w}$ are as defined above, and $E(q)$ denotes the expected output.

To assess the importance of the risk parameters for the performance of the marketing channel, we determine the agency (coordination) costs $(A C)$ of the whole marketing channel as the difference between the first-best optimal solution and the second-best optimal solution as follows: ${ }^{6}$

$$
A C=E\left(\pi_{r}^{*}+\pi_{w}^{*}+\pi_{p}^{*}\right)-E\left(\pi_{r}+\pi_{w}+\pi_{p}\right)
$$

The first-best optimal solution of the marketing channel, $E\left(\pi_{r}^{*}+\pi_{w}^{*}+\pi_{p}^{*}\right)$, is obtained by setting $\rho_{w}=\rho_{p}=0$. These restrictions imply that also the futures market is eliminated from the model: $Z_{p}=Z_{w}=\mu_{F}=\sigma_{\varepsilon F}=0$ and $\sigma_{F}^{2}=1$. 
Considering the empirical values of $c_{w}, c_{p}, d_{w}, d_{p}, \sigma^{2}, \bar{W}_{w}$ and $\bar{W}_{p}$ as given, then from (22) it follows that $S=\sigma^{2}$, (24) gives $\alpha_{p}=c_{p} /\left(c_{p}+c_{w}\right)$, (26) then shows that $\alpha_{w}=1$ so that $e=1 /\left(c_{p}+c_{w}\right)$ according to (15). Next we can compute $\beta_{p}$ and $\beta_{w}$ by (17) and (23), respectively, to finally derive the expectations and variances of the profits of the respective MCMs along the lines of (1) through (12). Now that all MCMs are risk-neutral, the futures market has become superfluous and the principal can give full incentives to the agent as the principal is not restricted anymore by the optimal trade-off according to which a higher incentive intensity can only be established at the cost of a higher risk premium (a higher risk premium is asked for by the agent as a consequence of the increased risk the agent faces at a higher incentive intensity). On the contrary, the second-best optimal solution of the marketing channel, $E\left(\pi_{r}+\pi_{w}+\pi_{p}\right)$, is obtained when producers and wholesalers are risk averse. Subsequently, we can determine the coordination costs when MCMs cannot trade futures contracts but are as risk averse as they are when they could trade on the futures market. This is done by setting $\sigma_{\varepsilon F}=$ $\mu_{F}=0$ and $\sigma_{F}^{2}=1$, and considering the empirical values of $\rho_{p}$ and $\rho_{w}$ obtained before imposing these restrictions as given. This analysis enables us to compare the coordination costs in the marketing channel with and without futures trade by MCMs.

\section{EMPIRICAL APPLICATION: DATA, ESTIMATION, AND RESULTS}

We apply our model to the Dutch potato industry. Every year, some eight million tons of potatoes are produced in the Netherlands, mainly on family farms. About half are ware potatoes, approximately $20 \%$ are seed potatoes, while the remaining 30\% are potatoes grown for starch. We focus on the ware potatoes as the prices of this type of potato exhibits the highest volatility estimates and is therefore considered as a more risky product than the other types of potatoes (Smidts, 1990). As far as the ware potato trade in the Netherlands is concerned, there is very little interference in the operation of a free market and hence "outside" involvement is at a minimum (e.g., Smidts, 1990; Young, 1977). Most ware potatoes are sold to wholesalers, and most of the wholesale trade has become concentrated in relatively few hands, as the major users, particularly the large retailers, processors and export markets, demand large quantities with tight specifications which only the larger wholesalers can meet. Because of this development in the market, the need has arisen to procure potatoes before harvest. In this respect, the potato futures contract of the Euronext Amsterdam Exchange fulfilled the function of price discovery (see Kuiper, Pennings, \& Meulenberg, 2002).

For the empirical analysis, Statistics Netherlands provided us with annual data from 1971 to 2003, for the following variables: the farm, export (i.e., wholesale) and retail prices (Euro/kg) of ware potatoes, all deflated by 
the consumer price index $(1990=1.00)$, the area planted $(1000 \mathrm{ha})$, the yield per hectare $(100 \mathrm{~kg} / \mathrm{ha})$, and the rent price of land (Euro/ha), deflated by the consumer price index. Furthermore, we obtained the futures price of potato from the Euronext Amsterdam Commodity Exchange from 1971 to 2003. From these time series, we derived the following variables of interest. First, all prices, spot, and futures prices were deflated by the consumer price index. The output quantity $q_{t}$ (million tons) in year $t$ was computed as the yield per hectare times the area planted (divided by $10^{4}$ ). We computed the conditional expectation of the consumer (retail) price, $p_{t}$, and denoted it as $\hat{\mathrm{E}}\left(p_{t} \mid I_{t-1}\right)$, assuming that the information set $I_{t-1}$ is common to all MCMs. Using data on yield per hectare and the number of hectares planted, the estimate of the expected output $E\left(q_{t} \mid I_{t-1}\right)$, denoted as $\hat{\mathrm{E}}\left(q_{t} \mid I_{t-1}\right)$, was obtained by the product of area planted and expected yield per hectare, where the expected yield per hectare was assumed to follow an autonomous positive linear time trend. Next, we turned to the estimation of $E\left(p_{t} q_{t} \mid I_{t-1}\right)$. For this, note that $p_{t} q_{t}=E\left(p_{t} \mid I_{t-1}\right) E\left(q_{t} \mid I_{t-1}\right)+E\left(p_{t} \mid I_{t-1}\right) \varepsilon_{q t}+\varepsilon_{p t} E\left(q_{t} \mid I_{t-1}\right)+\varepsilon_{p t} \varepsilon_{q t}$, where $\varepsilon_{p t}=p_{t}-E\left(p_{t} \mid I_{t-1}\right)$ and $\varepsilon_{q t}=q_{t}-E\left(q_{t} \mid I_{t-1}\right)$ are the unexpected components of $p_{t}$ and $q_{t}$, respectively, and $\varepsilon_{p t} \varepsilon_{q t}$ represents the covariance of $p_{t}$ and $q_{t}$, which we may expect to be negative. Consequently, $E\left(p_{t} q_{t} \mid I_{t-1}\right)=E\left(p_{t} \mid I_{t-1}\right)$ $E\left(q_{t} \mid I_{t-1}\right)+E\left(\varepsilon_{p t} \varepsilon_{q t} \mid I_{t-1}\right)$. Now, to estimate $E\left(p_{t} q_{t} \mid I_{t-1}\right)$, we simply regressed $p_{t} q_{t}$ on a constant and $\hat{\mathrm{E}}\left(p_{t} \mid I_{t-1}\right) \hat{\mathrm{E}}\left(q_{t} \mid I_{t-1}\right)$. In this way, $\hat{\mathrm{E}}\left(p_{t} \mid I_{t-1}\right) \hat{\mathrm{E}}\left(q_{t} \mid I_{t-1}\right)$ extracts all the information of interest out of $\varepsilon_{p t} \varepsilon_{q t}$ since the regression residuals are orthogonal to $\hat{\mathrm{E}}\left(p_{t} \mid I_{t-1}\right) \hat{\mathrm{E}}\left(q_{t} \mid I_{t-1}\right)$. Hence, the fit of the regression is denoted as $\hat{\mathrm{E}}\left(p_{t} q_{t} \mid I_{t-1}\right)$. To continue, the estimate of $\varepsilon_{t}$, denoted as $\bar{\varepsilon}_{t}$, was obtained by subtracting $\hat{\mathrm{E}}\left(p_{t} q_{t} \mid I_{t-1}\right)$ from $p_{t} q_{t}$. The estimate of $\sigma_{\varepsilon}^{2}$, denoted as $\hat{\sigma}_{\varepsilon}^{2}$, was simply computed as the fit of a regression of $\varepsilon_{t}^{2}$ on a constant. Similarly, using the data on $F_{t, t-1}$ and $F_{t, t}$ the estimates of $\sigma_{\varepsilon F}, \mu_{F}$ and $\sigma_{F}^{2}$, denoted as $\hat{\sigma}_{\varepsilon F}, \hat{\mu}_{F}$ and $\hat{\sigma}_{F}^{2}$, respectively, were obtained.

Finally, having data on $\bar{W}_{p t}$ and $\bar{W}_{w t}$ too, we are only left with the estimation of $c_{p}, c_{w}, d_{p}, d_{w}$ and $\alpha_{p}$ being the unknown parameters in the model. In order to estimate these parameters, we need to derive estimation equations. According to (15), we can substitute $c_{p} e$ for $\alpha_{p} \alpha_{w}$ into (3) and into (17), to obtain after substituting for $\beta_{p}$

$$
\begin{aligned}
W_{p t}-\bar{W}_{p t}= & d_{p}+c_{p} e_{t} x_{t}-0.5 c_{p} e_{t}^{2}+c_{p} e_{t} \hat{\mu}_{F} \hat{\sigma}_{\varepsilon F} / \hat{\sigma}_{F}^{2}-0.5 \hat{\mu}_{F}^{2} / \hat{\sigma}_{F}^{2} \rho_{p t} \\
& +0.5 c_{p}^{2} e_{t}^{2} \rho_{p t} \widehat{S}
\end{aligned}
$$

Similarly, substituting $c_{p} e / \alpha_{p}$ for $\alpha_{w}$ in (23) and then substituting for $\alpha_{w}$ and $\beta_{w}$ in (2), yields

$$
\begin{aligned}
W_{w t}-\bar{W}_{w t}-\bar{W}_{p t}= & d_{p}+d_{w}+c_{p} e_{t} x_{t} / \alpha_{p}-c_{p} e_{t}^{2} / \alpha_{p}+0.5\left(c_{p}+c_{w}\right) e_{t}^{2} \\
& -0.5 \hat{\mu}_{F}^{2} / \hat{\sigma}_{F}^{2} \rho_{p t}+0.5 c_{p}^{2} e_{t}^{2} \rho_{p t} \widehat{s}+\hat{\mu}_{F} \hat{\sigma}_{\varepsilon F} c_{p} e_{t} / \hat{\sigma}_{F}^{2} \alpha_{p} \\
& -0.5 \hat{\mu}_{F}^{2} / \hat{\sigma}_{F}^{2} \rho_{w t}+0.5\left[\left(1-\alpha_{p}\right) / \alpha_{p}\right]^{2} c_{p}^{2} e_{t}^{2} \rho_{w t} \widehat{s}
\end{aligned}
$$


After substituting (28) and (29) for $\rho_{w}$ and $\rho_{p}$, respectively, into (33) and (34), and modeling the deterministic terms $d_{p}$ and $d_{w}$ as linear trends, giving $d_{p t}=d_{p 0}+d_{p 1} t$ and $d_{w t}=d_{w 0}+d_{w 1} t$, we can estimate the unknown parameters $\alpha_{p}, c_{p}, c_{w}, d_{p 0}, d_{p 1}, d_{w 0}$, and $d_{p 1}$ in the two-equation system by full information maximum likelihood (FIML).

The FIML estimates of the unknown parameters in (33) and (34) are presented in Table 1 . The estimate for $\alpha_{p}$ is significant and nicely fits within the expected constraints $0<\alpha_{p}<1$. The estimates of the marginal cost terms $c_{p}$ and $c_{w}$ are positive and significant as well. However, with respect to the slopes of the trend terms in the cost functions, only the slope of the trend term of the producers' cost function, $d_{p 1}$, tend to be significant. Its negative sign indicates technological advances in agricultural production. Having obtained the estimates of the above-mentioned parameters, we now compute the estimates of the following variables: $\alpha_{w t}, \alpha_{p} \alpha_{w t}, \rho_{p t}, \rho_{w t}, \beta_{p t}$ and $\beta_{w t}$.

The estimates of the incentive parameters for producers, $\alpha_{p} \alpha_{w t}$, with and without futures market are compared with the first-best situation (i.e., when producers and wholesalers are risk neutral) and are shown in Figure 1. The estimates of the incentive intensity for the case with futures trade are higher than the estimates for the case without futures trade. The incentive intensity of producers increased from 0.24 in 1971 to 0.31 in 2003 in the case of futures trade, whereas it increased from 0.14 in 1971 to 0.25 in 2003 in the case without futures trade. This result shows that the futures market offers producers a

TABLE 1 Estimates of $\alpha_{p}, c_{p}, c_{w}, d_{p 0}, d_{p 1}, d_{w 0}$ and $d_{p 1}$ Obtained by FIML Applied to Eqs. (33) and (34)

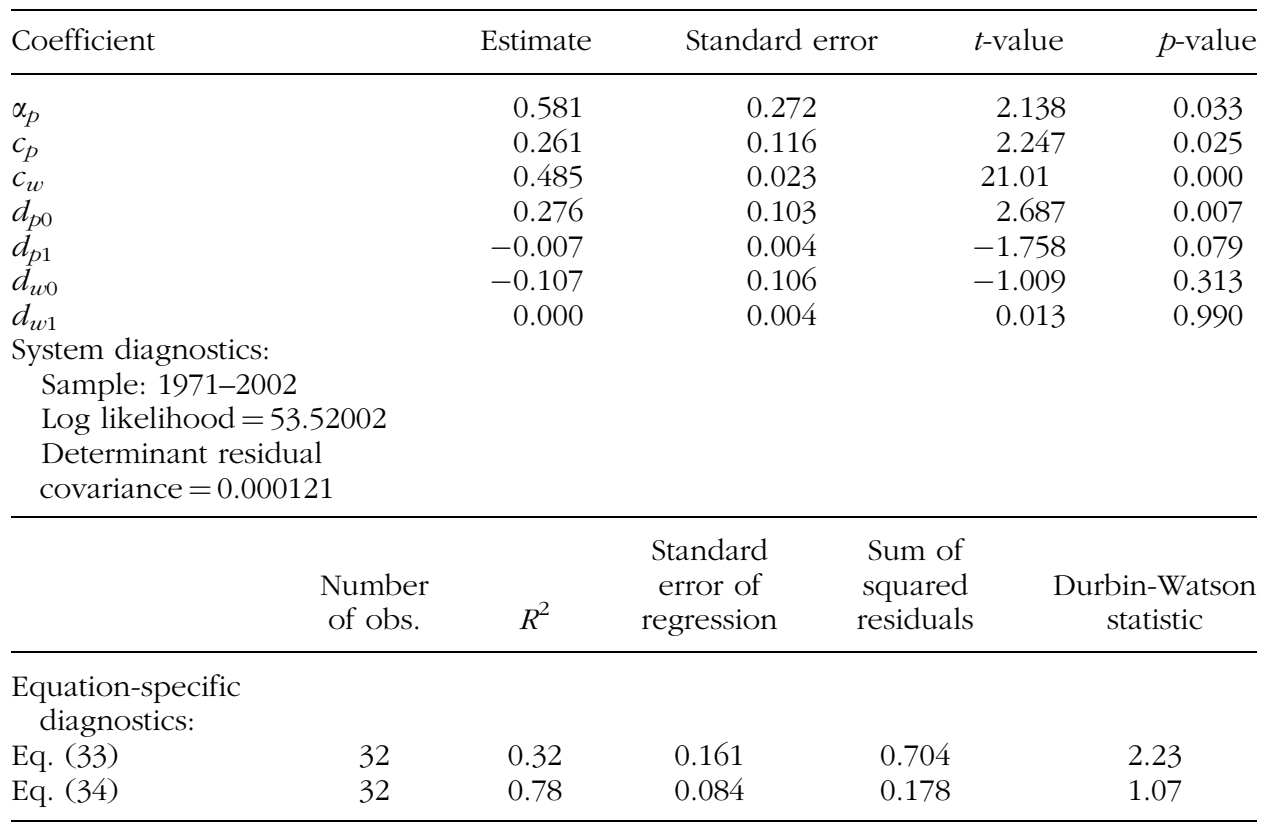




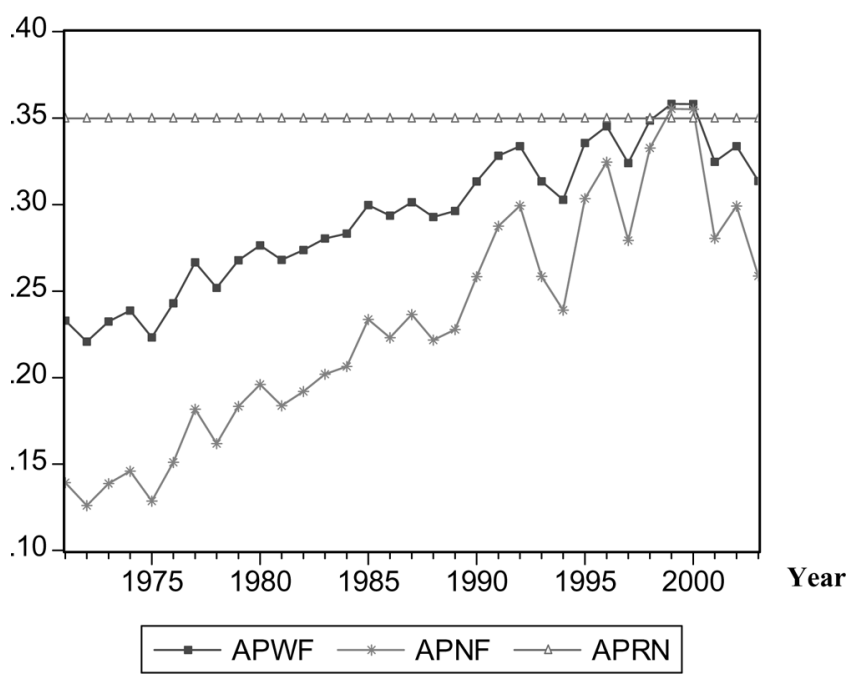

FIGURE 1 Producers' incentive intensity $\alpha_{p} \alpha_{w t}$ with futures (APWF), without futures (APNF), and under risk neutrality (APRN).

risk-management instrument in such a way that the wholesalers can give more incentives to the producers. As expected, most incentives can be given in case of risk neutrality, although remarkably, around 2000, where the three graphs converge, the incentive intensity seems to be hardly affected by the risk aversion of the producers. This result may indicate an improvement of coordination among wholesalers and producers.

Similarly, the estimates of the incentive intensity from retailers to wholesalers, $\alpha_{w t}$, with and without futures market are compared with the first-best

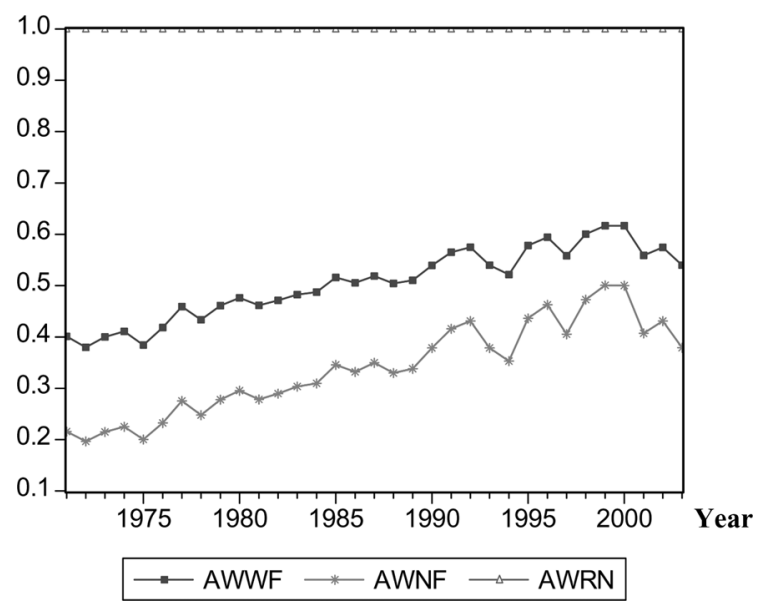

FIGURE 2 Wholesalers' incentive intensity $\alpha_{w t}$ with futures (AWWF), without futures (AWNF), and under risk neutrality $(\mathrm{AWRN}=1)$. 
situation and are displayed in Figure 2. In the same vein, the estimates of the incentive intensity to the wholesalers for the case that they (i.e., the wholesalers) trade futures are higher than for the case without futures trade. The incentive intensity for the wholesalers increased from 0.40 in 1971 to 0.62 in 2000 in the case of futures trade, and increased from 0.22 in 1971 to 0.50 in 2000 in the case without futures trade. Nevertheless, as compared to those of the producers, these estimates do not attain the optimal incentive intensity, showing the reduction in incentive intensity as a consequence of the risk aversion.

In contrast to the incentive parameters that show positive trending patterns, the fixed compensations for producers (wholesalers), $\beta_{p t}\left(\beta_{w t}\right)$, show negative trending patterns over the years. We compare these fixed compensations with their respective first-best situations, in turn. As shown in Figure 3, producers fixed compensation for the case with futures trade is more close to the first-best level most of the time than for the case without futures. This is again an indication for the positive impact of the futures market for coordination performance in the marketing channel. Furthermore, it is of interest to see that before 1990 the actual fixed compensation was too high compared to its first-best level, while after 1990, there are some years with an overinvestment by the negative fixed compensations.

Similarly, the wholesalers' fixed compensations show negative trending patterns and started to become negative at the beginning of the nineties (see Figure 4). It is interesting to note that the wholesalers' first-best fixed compensations were negative throughout the period of study, and much lower than the second-best estimates, which hardly differ between the cases with and without futures. So, as we also observed for the incentive intensi-

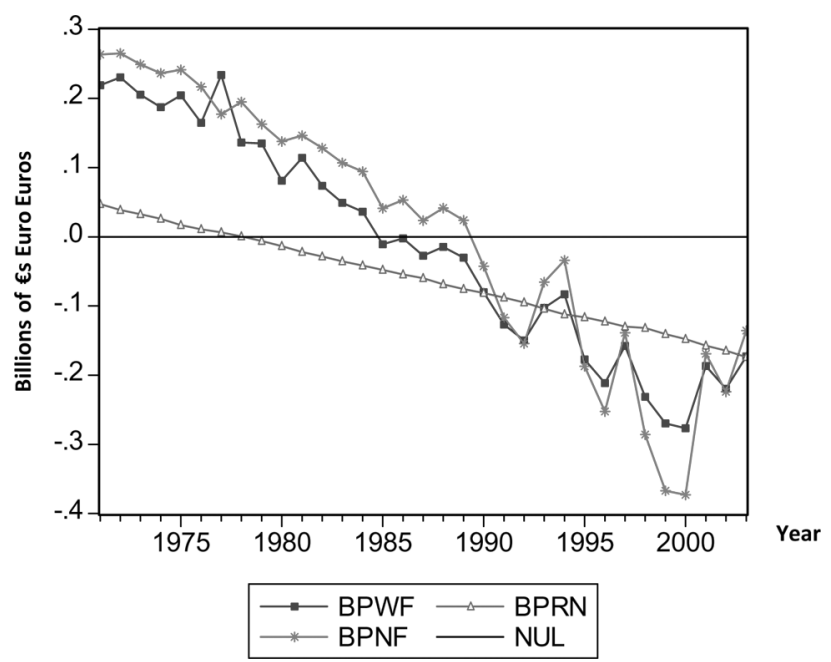

FIGURE 3 Producers' fixed compensation with futures (BPWF), without futures (BPNF), and under risk neutrality (BPRN). 


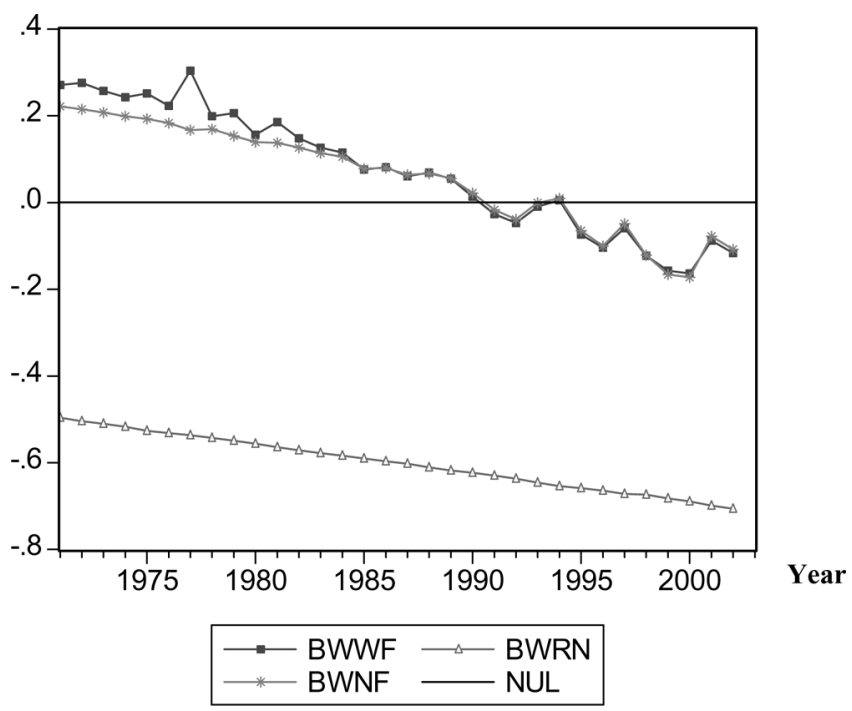

FIGURE 4 Wholesalers' fixed compensation with futures (BWWF), without futures (BWNF), and under risk neutrality (BWRN).

ties, the coordination between retailers and wholesalers is still considerably distant from first-best results.

The increase in the incentive intensity and the decrease and negativity of the fixed compensation payments to producers and wholesalers has implications for financial risk allocation in the marketing channel. The computed variance of profits of producers in (11) and wholesalers in (12) show slightly increasing trending patterns both in the case with and without futures market, whereas that of the retailers in (7) shows decreasing trending patterns that are quite pronounced (see Figure 5). The graphs in Figure 5 clearly show that of all MCMs, the retailers take most of the risk on their part, as we expect them to do as the single risk-neutral MCM. Nevertheless, their risk is much lower in the case of futures trade, indicating that they bear less risk if the wholesalers and producers use the futures market to manage their risk. So, interestingly, of all the MCMs, it is the retailer who profits most from the futures market in the sense of risk reduction, while, in fact, the retailer is not using the futures market as a risk-management instrument since the retailer is considered risk-neutral. Hence, it is to be expected that a reduction of risk within the marketing channel as a consequence of the functioning of a futures market, will especially be expressed in a reduction of risk on the part of the retailers.

The estimates of the risk parameters of the producers (wholesalers), $\rho_{p t}\left(\rho_{w t}\right)$, are depicted in Figure 6. Although we did not use them in the simulations, we estimated these risk parameters in case there is no futures market by imposing the restrictions $\sigma_{\varepsilon F}=\mu_{F}=0$ on (28) and (29), while further using the empirical data and coefficient estimates used for and obtained from estimating (33) and (34). This implies that the estimates 


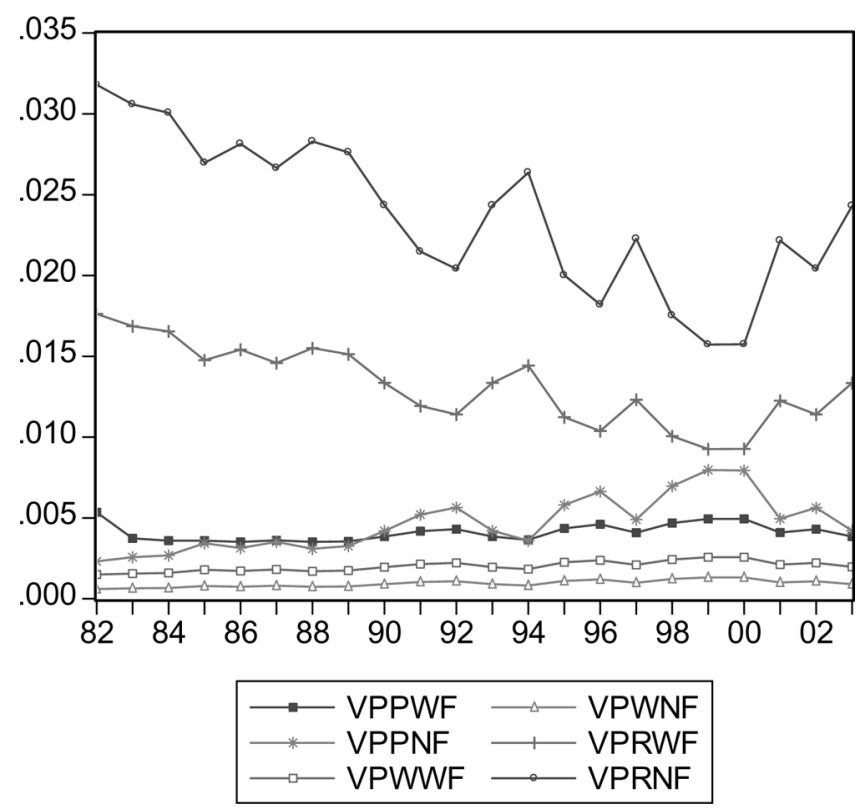

FIGURE 5 Variance of profits of wholesalers with futures (VPWWF) and without futures (VPWNF), variance of profits of producers with futures (VPPWF) and without futures (VPPNF), and variance of profits of retailers with futures (VPRWF) and without futures (VPRNF).

for the risk parameters are derived on the basis of data that are the result of MCMs' behavior under the actual situation in which they can trade on the futures market, while being subjected to the restrictions implying that there is no futures market. Consequently, the simulated risk parameter without futures market will be lower than the one obtained with futures market, because the former must indicate that the risk-averse MCMs are less risk-averse than they are really. This stems from the fact that in the real situation there is a futures market available by which they can manage part of their risk, leading to behavior that is too risky according to their absolute risk-aversion if there would not be a futures market. This is exactly what we observe in Figure 6. Furthermore, the figure also shows that for both wholesalers and producers the risk coefficient considerably decreases over time. Nevertheless, the wholesalers are much more risk averse than the producers. In fact, from 1980 onward, the producers even become risk-seekers as their risk coefficient turns into negative values. This result explains our earlier conclusions that the contract parameters in the relationship between wholesalers and producers attain first-best levels whereas those in the relationship between retailers and wholesalers do not.

In the above discussions, our results have shown that retailers had to take less risk on their part because the risk-averse producers and wholesalers used the futures market to reduce their variability in profits. It is, therefore, 


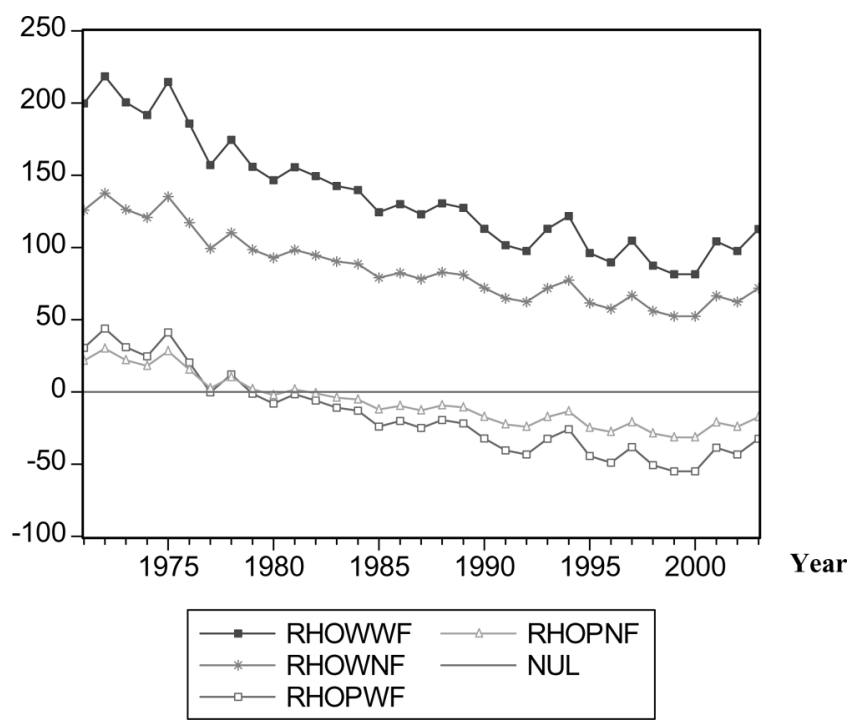

FIGURE 6 Wholesalers' absolute risk aversion coefficient with futures (RHOWWF) and without futures (RHOWNF); producers' absolute risk-aversion coefficient with futures (RHOPWF) and without futures (RHOPNF).

imperative that producers and wholesalers hedge against the variability in the profits over time. Assuming that producers and wholesalers trade futures contracts in addition to the spot market transactions, we estimate their respective optimal dynamic hedge ratio in (30) and (31). In this instance, producers are assumed to sell futures contracts of their produce, whereas the wholesalers are assumed to buy futures contracts. Complying with the decreases in the wholesalers' degree of risk aversion, the optimal dynamic hedge ratio for wholesalers decreased from $14 \%$ in 1971 to $10 \%$ in 2003 , see Figure 7.

Similarly, the producers' optimal dynamic hedge ratios decreased from about $38 \%$ in 1982 to $18 \%$ in 2003 , complying with the decrease in the degree of risk aversion, see Figure 8 . The results also show that over the period of study, producers hedge more than wholesalers do.

What we did not show in Figure 7 is that the hedge ratio is in fact negative instead of positive, because the wholesaler buys a "negative" amount on the futures market. In the model the wholesalers are positioned as long hedgers (buyers), as seen in (10), but based on the empirical data, this results in a negative hedging amount implying that the wholesalers, like the producers, go short instead of long. Given the empirical observation that most potato contracts between wholesalers and growers in the Netherlands are closed before or during the planting period, and the fact that most of the wholesale trade is in the hands of farmer cooperatives, wholesalers in fact take over the "short" position of the producers by taking away most of the 


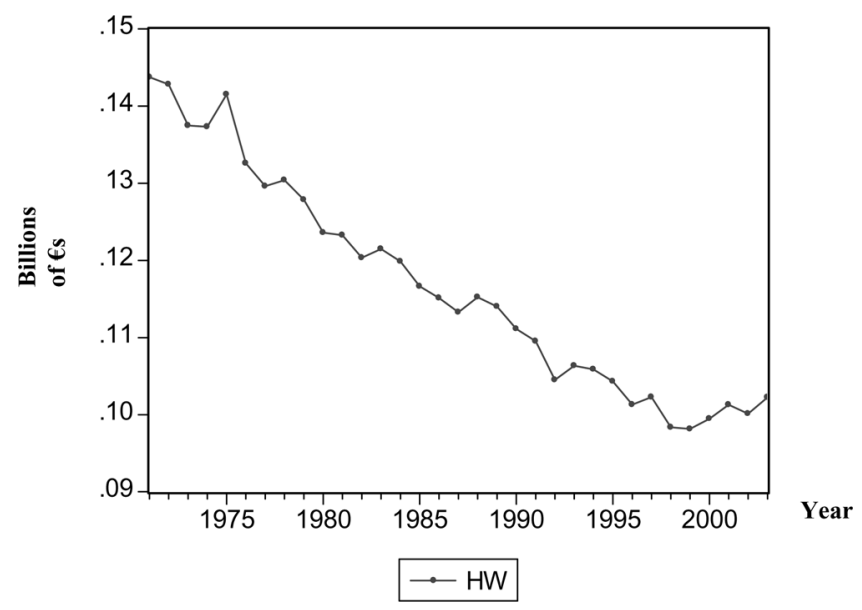

FIGURE 7 Wholesalers' optimal dynamic hedge ratio (HW).

price risk from the producers. This may give room for the producers to act as speculators as shown by the negative coefficient of risk aversion, so that they may still sell more on the futures market than the wholesalers, in spite of the fact that the wholesalers have a higher coefficient of risk aversion than the producers.

To assess the coordination efficiency, we computed the coordination costs of the marketing channel involving producers, wholesalers and retailers. Intuitively, as a result of increases in the incentives to producers and wholesalers the coordination costs of the marketing channel have generally decreased over time both with and without futures trade. The coordination

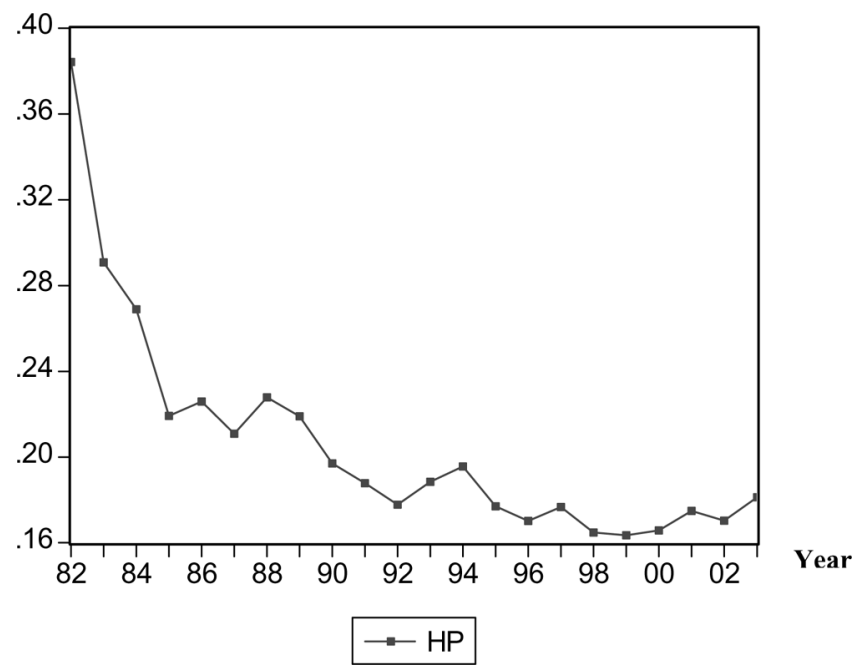

FIGURE 8 Producers' optimal dynamic hedge ratio (HP). 


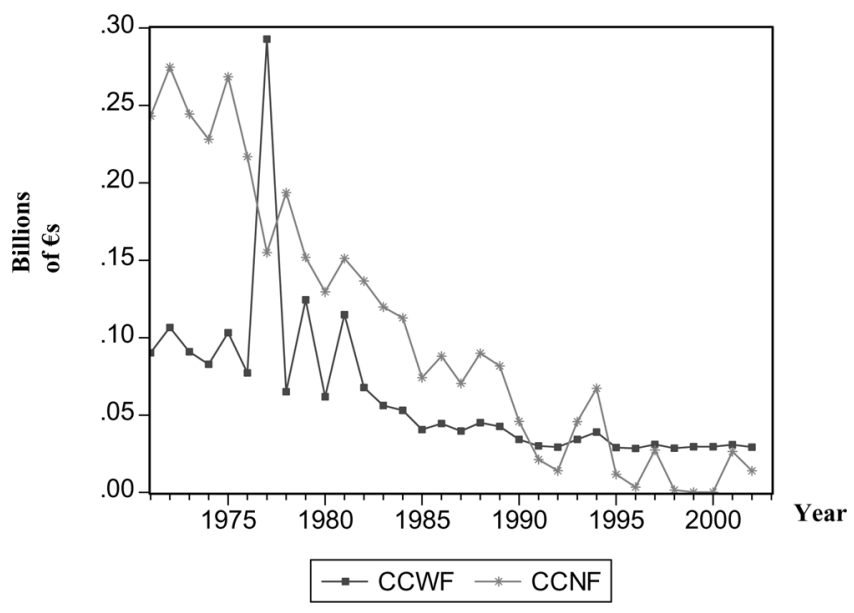

FIGURE 9 Coordination costs of the marketing channel with futures market (CCWF) and without futures markets (CCNF).

costs of the marketing channel with (without) futures trade decreased from about 0.09 billion euros ( 0.24 billion euros) in 1971 to 0.03 billion euros ( 0.014 billion euros) in 2002 (see Figure 9). In Figure 10, we show the expectations of the total profits of the marketing channel for three situations: the optimal (i.e., first-best) situation (i.e., risk neutrality), the situation with futures trade, and the situation without futures trade. The difference between the expected profits for the optimal situation and for the situation with futures trade are the coordination costs for the situation with futures as

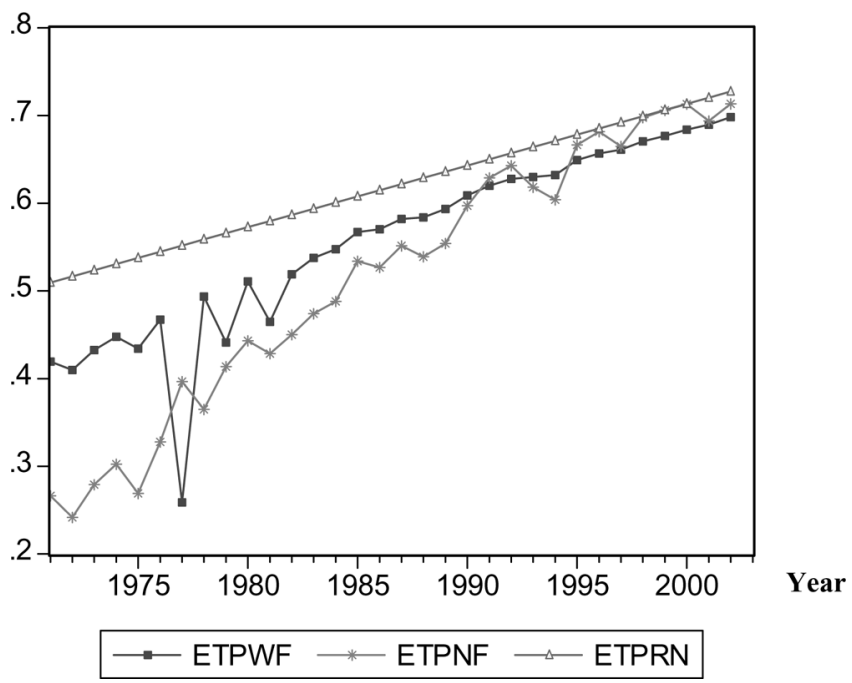

FIGURE 10 The expectation of total profit of the marketing channel with futures (ETPWF), without futures (ETPNF), and under risk neutrality (ETPRN). 


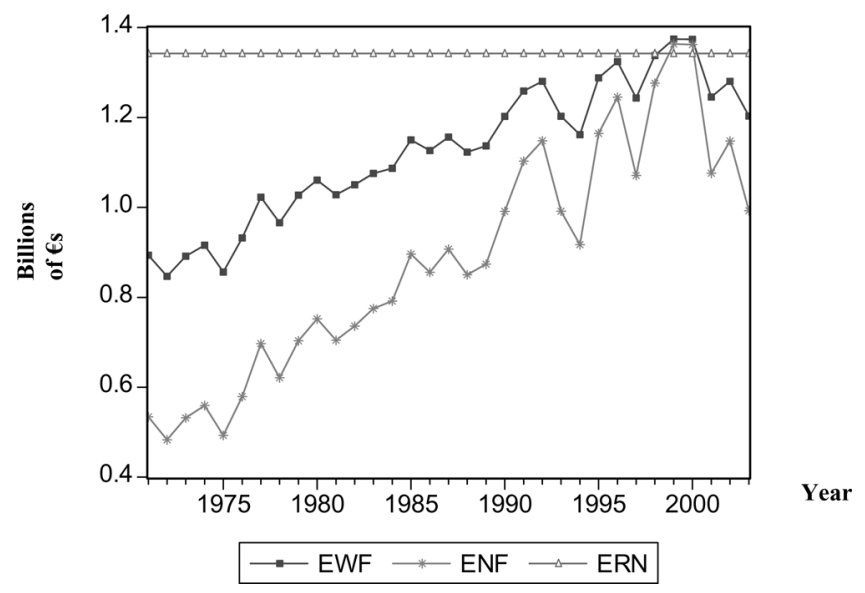

FIGURE 11 The expectation of retail (output) value with futures (EWF), without futures (ENF), and under risk neutrality (ERN).

shown in Figure 9. Similarly, the difference between the expected profits for the optimal situation and for the situation without futures trade are the coordination costs for the situation without futures, also shown in Figure 9. The graphs are consistent with earlier research showing that increases in incentives reduce the coordination costs of the marketing channel (Kuwornu, Kuiper, Pennings, \& Meulenberg, 2005a). A careful look at Figure 10 reveals that the coordination efficiency of the marketing channel has been greatly improved as the expected profits of the marketing channel closely approach the first-best profits from 1995 onward. This result is further confirmed by the fact that the expectations of the retail value for the cases with and without futures also reach first-best levels (see Figure 11). A point worth noting is that the coordination costs with futures are generally lower than those without futures. This result complies with the role of futures markets in providing information regarding prices.

In order to evaluate the validity of the model, we examine how the estimated payments explain the actual payments for producers and

TABLE 2 Parameter Estimates in the Regression of the Actual Payment to the Producers (WP) on the Variable and Fixed Payment Components That Were Estimated by the Model

\begin{tabular}{lcccr}
\hline Variable & Estimate & $S E$ & $t$-value & $p$-value \\
\hline Intercept & 0.031 & 0.118 & 0.261 & 0.796 \\
$\hat{\alpha}_{p} \hat{\alpha}_{w t} x_{t}$ & 0.873 & 0.351 & 2.489 & 0.019 \\
$\hat{\beta}_{p t}$ & 0.950 & 0.262 & 3.632 & 0.001 \\
\hline
\end{tabular}

Note. Sample: 1971-2003; number of observations $=33 ; R^{2}=0.31 ; R_{\text {adj }}^{2}=0.26 ; S E$ resid. $=0.15$; sum squared resid. $=0.70 ;$ Durbin-Watson $=2.22 ; F(3,30)$.

Statistic testing for the joint hypothesis that the intercept is zero and the coefficients of $\hat{\alpha}_{p} \hat{\alpha}_{w t} x_{t}$ and $\hat{\beta}_{p t}$ are equal to one $=0.10(p$-value $=0.96)$. 
TABLE 3 Parameter Estimates in the Regression of the Actual Payment to the Wholesalers (WW) on the Variable and Fixed Payment Components That Were Estimated by the Model

\begin{tabular}{lrrrr}
\hline Variable & Estimate & $S E$ & $t$-value & $p$-value \\
\hline Intercept & -0.029 & 0.069 & -0.424 & 0.675 \\
$\hat{\alpha}_{w t} x_{t}$ & 1.052 & 0.103 & 10.163 & 0.000 \\
$\hat{\beta}_{w t}$ & 0.986 & 0.150 & 6.567 & 0.000 \\
\hline
\end{tabular}

Note. Sample: 1971-2003; number of observations $=33 ; R^{2}=0.78 ; R_{\mathrm{adj}}^{2}=0.77 ; S E$ resid. $=0.08$; sum squared resid. $=0.17$; Durbin-Watson $=1.02 ; F(3,30)$.

Statistic testing for the joint hypothesis that the intercept is zero and the coefficients of $\hat{\alpha}_{w t} x_{t}$ and $\hat{\beta}_{w t}$ are equal to one $=0.26(p$-value $=0.85)$.

wholesalers. A regression of the actual payments on the estimated variable and fixed payment components for producers shows that the estimated payments are efficient predictions and explain about $31 \%$ of the actual payments. See the results tabulated in Table 2 .

Similarly, a regression of the actual payments on the estimated variable and fixed payment components for wholesalers reveals that the estimated payments are efficient predictions and explain about $78 \%$ of the actual payments, as shown by the results displayed in Table 3 .

Next, we conducted normality tests regarding the distributional assumption (in applying the certainty equivalent approach) for the profits of producers and wholesalers. The results show that the profits of producers and wholesalers, computed with the costs estimated by the model, are normally distributed. The $p$-value of the Jarque-Bera statistic is 0.55 for the producers' profits and 0.16 for the wholesalers' profits, justifying the application of the certainty equivalent model in this article.

\section{CONCLUSIONS}

In this article, we extended the widely known two-stage principal-agent model into a three-stage model involving producers, wholesalers, and retailers to assess incentives, coordination costs, risk, risk aversion, and risk management strategies in an agricultural marketing channel. The model allows the risk-averse producers and wholesalers to trade futures in combination with their contractual relationships in the spot markets.

We applied the model to assess financial risk allocations in the Dutch potato marketing channel. The results showed that the risk-neutral retailers take less risk on their part as the wholesalers and producers become less risk averse and use the futures market for hedging purposes. Not only the producers but also the wholesalers take a short position (i.e., are selling) on the futures market, complying with the observation that in the Netherlands wholesalers already close contracts with the producers before or during planting for the new harvest, and most of this wholesale trade is 
in the hands of farmers' cooperatives. Consequently, wholesalers take over most of the price risk from the producers (farmers), leaving them some room for speculation.

Nevertheless, the producers still hedge more than the wholesalers, although for both, the optimal hedge ratio decreased: from 14\% in 1971 to $10 \%$ in 2003 for the wholesalers, and from 38\% in 1982 to $18 \%$ in 2003 for the producers. The decreases in risk aversion and the optimal hedge ratios go together with a considerable improvement of coordination between wholesalers and producers, as indicated by the convergence of the estimated contract parameters (regarding the compensation payments by wholesalers to producers) to first-best incentive intensity values. Coordination between retailers and wholesalers seems to be open for further improvement, although the benefits of these improvements will be minor for the marketing channel as a whole, because total channel profit has already come very close to the first-best level of profit that the channel will reach in case of risk neutrality of all channel members. Interestingly, the coordination costs of the marketing channel in the case that channel members trade futures are generally lower than in the case that they do not trade futures. This demonstrates the role of futures markets in providing information regarding prices to MCMs.

The implications of our results for business practice are as follows. First, profit risk of the MCMs reduced as a result of futures trade. Hence, MCMs in FMCs should consider commodity futures contracts as a means of reducing risk in their profits (returns), as prices of agricultural products are highly volatile (e.g., Maynard, Wolf, \& Gearhardt, 2005; Tomek \& Peterson, 2006). Second, since futures trade by MCMs reduced the coordination (agency) costs of the marketing channel, MCMs in FMCs may seriously benefit from the use of futures markets. There are MCMs, however, who perceive hedging as difficult. Therefore, education efforts by the exchanges may be valuable.

Finally, we contend that our results can be generalized to other industries where futures contracts exist for the relevant commodities traded. However, in practice, many MCMs are reluctant to trade futures contracts because of the complexity of these contracts. In fact, MCMs are confronted with a wide variety of risk management instruments, thereby making their choice of the risk management instrument(s) a complex task (Pennings, Isengildina-Massa, Irwin, Garcia, \& Good, 2008). Therefore, it is important that futures markets continue their efforts to tailor the contract specification to the needs of the hedgers.

\section{NOTES}

1. In line with the classic agency model, the linear contract in (2) and (3) is chosen because it corresponds to real-world settings (e.g., Knoeber, 1999; Allen \& Lueck, 2002). Moreover, Holmstrom and Milgrom (1987) have shown that the optimal compensation scheme for providing incentives over time 
to an agent with a constant absolute risk-aversion during the duration of the contract is a linear function of the end-of-period results, such as revenues, costs, or profits. This result is based on the fact that a linear contract provides more uniform incentive than a nonlinear contract, as can be seen by viewing the annual output as the outcome of many small, daily actions of the agent. Seen from this perspective, a nonlinear contract may create unintentional or nonuniform incentives for the agent in the course of the year, depending on the agent's performance to date (Gibbons, 2005).

2. If the futures price at maturity, $F_{t, t}$, exceeds the futures price at the initiation of the contract, $F_{t, t-1}$, the farmer pays the futures exchange the difference between these prices multiplied by the volume of futures contract sold, $Z_{p}$. We assume that delivery settlement or cash settlement characteristics of the futures contract do not influence the gains or losses from the futures trade. In recent years, the Euronext Amsterdam Commodity Exchange, from where we obtained the futures price data, has embarked on cash settlement of futures contracts.

3. Similarly, if the futures price at maturity, $F_{t, t}$, exceeds the futures price at the initiation of the contract, $F_{t, t-1}$, the wholesaler pays the futures exchange the difference between these prices multiplied by the volume of futures contract bought, $Z_{w}$.

4. The participation constraint suggests that the agent must at least derive a minimum level of expected utility from his or her contractual relationship with the principal; hence, this is an inequality constraint. However, Mitra (1983) has shown that if leisure is assumed as a normal good, then the participation constraint holds with equality in equilibrium. By definition, the demand for normal goods rises with increases in income (i.e., the income elasticity of demand is positive for normal goods). The incentive compatibility constraint reflects the restriction that the principal can observe the agent's output but not the agent's action or effort. In this sense the effort exerted by the agent is optimal from the agent's own point of view.

5. The hedge ratio of the producer is the amount of output that the producer sells in the futures market as a proportion of the output that the producer sells in the spot market. Similarly, the wholesaler's hedge ratio is the proportion of the quantity that the wholesaler buys in the futures market as a proportion of the total amount of produce purchased by the wholesaler on the spot market.

6. Agency (coordination) costs may include ex ante information search costs associated with adverse selection (hidden information) problems, and/or ex-post monitoring and enforcement costs associated with moral hazard problems. These costs are believed to be the main reasons for which the marketing channel cannot achieve the first best optimal solution. Among other objectives, we examine the role of incentives in reducing coordination costs of the marketing channel with and without futures trading.

\section{REFERENCES}

Allen, D. W. \& Lueck, D. (2002). The nature of the farm: Contracts, risk, and organization in agriculture. Cambridge, MA: MIT Press.

Birchler, U. \& Bütler, M. (2007). Information economics. London: Routledge.

Boehlje, M. (1996). Industrialization of agriculture: What are the implications? Choices (First Quarter), 30-33.

Competition Commission. (2000). Supermarkets: A report on the supply of groceries from multiple stores in the United Kingdom. Cm 4842. London: TSO.

Dawson, P. J., Tiffin, A. L., \& White, B. (2000). Optimal hedging ratios for wheat and barley at the LIFFE: A GARCH approach. Journal of Agricultural Economics, 51 (2): 147-161.

Ederington, L. H. (1979). The hedging performance of the new futures markets. Journal of Finance, 34 (1): 157-170.

Eisenhardt, K. M. (1989). Agency theory: An assessment and review. Academy of Management Review, 14 (1): 57-74.

Folkerts, H. \& Koehorst, H. (1998). Challenges in international food supply chains: Vertical co-ordination in the European agribusiness and food industries. British Food Journal, 100 (8): 385-388. 
Furubotn, E. G. \& Richter, R. (1997). Institutions and economic theory-the contribution of the new institutional economics. Ann Arbor, MI: University of Michigan Press.

Gibbons, R. (2005). Incentives between firms (and within). Management Science, 51 (1): $2-17$.

Hingley, M. K. (2005). Power to all our friends? Living with imbalance in supplier-retailer relationships. Industrial Marketing Management, 34 (8): 848-858.

Holmstrom, B. \& Milgrom, P. (1987). Aggregation and linearity in the provision of intertemporal incentives. Econometrica, 55 (2): 303-328.

Knoeber, C. R. (1999), Land and livestock contracting in agriculture: A principalagent perspective. In B. Bouckaert and G. De Geest (Eds.), Encyclopedia of Law E Economics, (pp. 1133-1153). Cheltenham, UK: Edward Elgar.

Knoeber, C. R. \& Thurman, W. N. (1995). "Don't count your chickens...": Risk and risk shifting in the broiler industry. American Journal of Agricultural Economics, 77, 486-496.

Kuiper, W. E., Pennings, J. M. E., \& Meulenberg, M. T. G. (2002). Identification by full adjustment: Evidence from the relationship between futures and spot prices. European Review of Agricultural Economics, 29 (1): 67-84.

Kuwornu, J. K. M., Kuiper, W. E., \& Pennings, J. M. E. (2004). Time series analysis of a principal-agent model to assess risk shifting in agricultural marketing channels: An application to the Dutch ware potato marketing channel. In G. Van Huylenbroeck, W. Verbeke, and L. Lauwers (Eds.), Role of Institutions in Rural Policies and Agricultural Markets, (pp. 255-271). New York: Elsevier.

Kuwornu, J. K. M., Kuiper, W. E., Pennings, J. M. E., \& Meulenberg, M. T. G. (2004). Agency theory, futures markets and risk shifting in commodity marketing channels. In H. J. Bremmers, S. W. F. Omta, J. H. Trienekens, and E. G. M. Wubben (Eds.), Dynamics in Chains and Networks, (pp. 510-517). Wageningen, Netherlands: Wageningen Academic Publishers.

Kuwornu, J. K. M., Kuiper, W. E., Pennings, J. M. E., \& Meulenberg, M. T. G. (2005a). Incentive provision and coordination costs in food marketing channels: A multi-stage channel agency theory perspective. Journal of Food Distribution Research, 36 (1): 95-100.

Kuwornu, J. K. M., Kuiper, W. E., Pennings, J. M. E., \& Meulenberg, M. T. G. (2005b). Time-varying hedge ratios: A principal-agent approach. Journal of Agricultural Economics, 56 (3): 417-432.

Martin, L. L. (1997). Production contracts, risk shifting, and relative performance payments in the pork industry. Journal of Agricultural and Applied Economics, 29 (2): 267-278.

Mattos, F., Garcia, P., \& Pennings, J. M. E. (2008). Probability weighting and loss aversion in futures hedging. Journal of Financial Markets, 11 (4): 433-452.

Maynard, L. J., Wolf, C., \& Gearhardt, M. (2005). Can futures and options markets hold the milk price safety net? Policy conflicts and market failures in dairy hedging. Review of Agricultural Economics, 27 (2): 273-286.

Milgrom, P. \& Roberts, J. (1992). Economics, organization and management. Englewood Cliffs, NJ: Prentice Hall. 
Mitra, P. K. (1983). A theory of interlinked rural transactions. Journal of Public Economics, 20 (2): 167-191.

Pennings, J. M. E. \& Meulenberg, M. T. G. (1997). The hedging performance in new agricultural futures markets: A note. Agribusiness: An International Journal, 13 (3): 295-300.

Pennings, J. M. E. \& Leuthold, R. M. (2000). The motivation for hedging revisited. Journal of Futures Markets, 20 (9): 865-885.

Pennings, J. M. E. (2004). A marketing-finance approach towards industrial channel contract relationships: A model and application. Journal of Business Research, 57 (6): 601-609.

Pennings, J. M. E., Isengildina-Massa, O., Irwin, S. H., Garcia, P., \& Good, D. L. (2008). Producers' complex risk management choices. Agribusiness: An International Journal, 24 (1): 31-54.

Reimer, J. J. (2006). Vertical integration in the pork industry. American Journal of Agricultural Economics, 88 (1): 234-248.

Smidts, A. (1990). Decision making under risk. (Wageningen Economic Studies No. 18). Wageningen: Pudoc.

Tomek, W. G. \& Peterson, H. H. (2006). Implications of commodity price behavior for marketing strategies. American Journal of Agricultural Economics, 87 (5): 1258-1264.

Young, N. A. (1977). The Dutch ware potato marketing system (Report No. 9). Ashford: Center for European Agricultural Studies.

Zhao, H. (2005). Incentive-based compensation to advertising agencies: A principalagent approach. International Journal of Research in Marketing, 22 (3): 255-275. 